\title{
Variação sazonal dos valores de bioquímica sérica de jiboias amazônicas (Boa constrictor constrictor) mantidas em cativeiro
}

\author{
Dennis José da Silva Lima ${ }^{1}$ \\ Renata Kelly Gonzaga Bastos ${ }^{2 *}$ \\ Larissa dos Santos Seixas ${ }^{2}$ \\ Monique Araújo Luz ${ }^{2}$ \\ Erika Renata Branco ${ }^{3}$ \\ Nazaré Fonseca de Souza ${ }^{3}$ \\ Carla Cristina Guimarães de Moraes ${ }^{4}$ \\ Andre Marcelo Conceição Meneses ${ }^{3}$

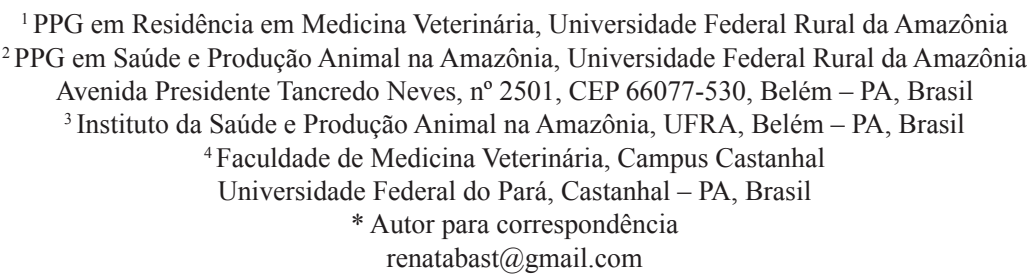

Submetido em 01/11/2011

Aceito para publicação em 03/08/2012

\section{Resumo}

Na região Norte do Brasil, as estações do ano não são bem definidas como acontece nas regiões Sul e Sudeste, devido ao clima equatorial quente e úmido, com um período mais chuvoso, conhecido como inverno amazônico, e um período menos chuvoso, conhecido como verão amazônico. Com esta pesquisa, objetivou-se avaliar a variação dos valores bioquímicos séricos de jiboias amazônicas correlacionadas com a sazonalidade da região. Foram realizadas análises bioquímicas séricas (AST, ALT, DHL, FA, cálcio, ácido úrico, fósforo, proteína total, albumina e globulina) de 31 serpentes da espécie Boa constrictor constrictor, mantidas em cativeiro. Levando em consideração a variável sazonalidade, observou-se que oito dos dez parâmetros são maiores no inverno em comparação ao verão (proteína total, albumina, globulina, ALT, AST, FA, DHL e cálcio) sendo que os valores de ALT, AST e cálcio mostraram ter diferenças estatísticas significantes no verão e inverno amazônicos, enquanto que os demais parâmetros parecem não ser influenciados pela sazonalidade. Esta foi a primeira pesquisa, em cativeiro, analisando o perfil bioquímico sérico serpentes Boa constrictor constrictor no Estado do Pará.

Palavras-chave: Bioquímica sérica; Boa constrictor constrictor; Cativeiro; Jiboias; Sazonalidade

\section{Abstract}

Seasonal variation of serum biochemical values of Amazonian snakes (Boa constrictor constrictor) kept in captivity. In northern Brazil, the seasons are not well defined compared to the South and Southeast regions, 
due to a hot and humid equatorial climate with a rainy season, known as the Amazonian winter, and a period with less rain, known as the Amazonian summer. The goal of this study was to evaluate the biochemical variation of serum from the Amazon Boa constrictor by correlating the values with the seasons of the region. A biochemical analysis of the serum was performed (AST, ALT, LDH, ALP, calcium, uric acid, phosphorus, total protein, albumin and globulin) using 31 individuals of Boa constrictor constrictor, which were kept in captivity. It was observed that eight of the ten parameters were higher in the winter compared to the summer (total protein, albumin, globulin, ALT, AST, ALP, LDH and calcium). The ALT, AST and calcium values had statistically significant differences for the summer and winter, while the other parameters appear to be influenced by seasonality. This was the first study of snakes kept in captivity that analyzed the serum chemistry profile of Boa constrictor constrictor from the state of Pará, Brazil.

Key words: Boa constrictor constrictor; Captivity; Seasonality; Serum chemistry; Snakes

\section{Introdução}

Na criação de serpentes em cativeiro é importante conhecer a biologia e a história natural de cada espécie mantida, de modo a minimizar os efeitos da resposta fisiológica ao estresse, que podem afetar a reprodução, o sistema imunológico e o metabolismo (KOLESNIKOVAS et al., 2006).

Tal modalidade de criação está aproximando estes animais cada vez mais para a clínica veterinária, onde a necessidade de informações sobre alterações fisiopatológicas é crescente (CAMPBELL, 2006b).

A jiboia (Boa constrictor) é o membro mais conhecido da família Boidae (MITCHEL, 2009) e pode ser encontrada em quase todas as partes do mundo, habitando principalmente as regiões temperadas e tropicais (KOLESNIKOVAS et al., 2006).

Subespécies desta família, como a Boa constrictor constrictor pode atingir até quatro metros de comprimento, possui cabeça longa, destacada do pescoço lateralmente, dentes longos, fortes e afados, corpo robusto no centro, cauda forte e preênsil (MOSMANN, 2001), e a pupila vertical, indica atividade noturna do animal, embora a prática mostre que também possuem atividade diurna, principalmente quando estão em cativeiro (IIZUKA et al., 1984). Esta subespécie se adapta bem ao cativeiro quando suas necessidades básicas como alimentação, sanidade, umidade e temperatura são supridas (FOWLER; CUBAS, 2001; MOSMANN, 2001).

Sabe-se que a concentração da maioria dos constituintes sanguíneos nos répteis apresenta variações fisiológicas importantes, que podem ser ocasionadas por vários fatores como alimentação, disponibilidade de água, hibernação (SANTOS, 2006), idade, sexo, condição nutricional, e principalmente a variação de temperatura corporal (CAMPBELL, 2006a).

Para regular a própria temperatura, estes animais dependem de ajustes comportamentais e de fontes externas de calor, a partir do controle da quantidade de superfície de pele exposta ao sol ou sobre superfícies quentes ou frias, cuja disponibilidade pode variar de acordo com a sazonalidade (BOVO et al., 2004), fato este, que torna a interpretação dos resultados bioquímicos um desafio para o veterinário de animais selvagens (CAMPBELL, 2006a).

A quantidade máxima de sangue que pode ser extraída é até $1 \%$ do peso, em média $2 \mathrm{~mL}$ de sangue por animal, sendo a veia caudal ventral a de eleição para obtenção da amostra, contudo não se consegue obter volumes maiores pela punção desta veia (CAMPBELL, 2006a). Outra forma de coleta é por cardiocentese, que segundo Mitchel (2009), o coração é rotineiramente utilizado como o local de punção venosa por ser facilmente visualizado quando o animal é posicionado em decúbito dorsal.

O sangue para avaliação bioquímica deve ser coletado em frasco com anticoagulante de heparina lítica, o EDTA não é recomendado, pois este pode lisar as células sanguíneas de alguns répteis (JACOBSON, 1987).

Levando em consideração que na região norte as estações do ano não são bem definidas, havendo apenas dois períodos distintos, um caracterizado por ser mais 
chuvoso (inverno amazônico) e o outro por ser menos chuvoso (verão amazônico), objetivou-se com esta pesquisa, avaliar a variação nos valores bioquímicos séricos de jiboias amazônicas criadas em cativeiro influenciados pela sazonalidade da região.

\section{Material e Métodos}

Foram utilizadas 31 serpentes adultas clinicamente saudáveis mantidas em cativeiro da espécie $B o a$ constrictor constrictor, sendo 17 machos e 14 fêmeas, provenientes do criatório comercial Sítio Xerimbabo, localizado no município de Santo Antônio do Tauá/PA (latitude 0109'09'S e longitude 48 07'46”O), registrado no IBAMA pelo no 192115 . Esses animais viviam em recintos devidamente higienizados, enriquecidos ambientalmente com troncos, lago, tocas e sem fonte de calor artificial, apenas janelas para entrada de luz solar.

A presente pesquisa teve autorização do Ministério do Meio Ambiente (MMA), Instituto Brasileiro do Meio Ambiente e dos Recursos Naturais Renováveis (IBAMA), Instituto Chico Mendes de Conservação da Biodiversidade (ICMBio), Sistema de Autorização e Informações em Biodiversidade (SISBIO), sob o número 16851.

Todos os animais foram submetidos à exame clinico, realizado de acordo com o descrito por Hiinarejos et al. (2007), na direção craniocaudal, incluindo inspeção da cavidade oral, dos orifícios nasais e da membrana ocular, palpando-se todo o corpo dos animais e finalizando com uma inspeção da cloaca. A pele e a superfície interior das escamas foram examinadas em busca de ácaros, problemas de muda, traumas, infecções ou quaisquer outra alteração que pudesse descartar os animais da amostragem. Foi realizado também hemograma de todos os animais, que apresentaram resultados dentro dos parâmetros de referência descritos na literatura.

As amostras de sangue foram obtidas dos períodos conhecidos como verão (agosto/2009) e inverno amazônico (janeiro/2010), com uma colheita no verão e outra no inverno. Os procedimentos iniciaram-se por volta das 07 h00min da manhã e se estendiam, até no máximo, as $10 \mathrm{~h} 00 \mathrm{~min}$, onde as temperaturas do dia são mais brandas. Todos os animais recebiam o mesmo tipo de alimentação (camundongos, ratos ou preás), porém antes das colheitas foram submetidos a jejum alimentar prévio de uma semana, para evitar regurgitação durante a manipulação.

Para realizar a colheita de sangue, dividiu-se topograficamente o corpo dos animais em três partes iguais e avaliou-se, principalmente, o final do primeiro terço cranial, onde foram observados movimentos que indicavam a posição anatômica do coração. Após localizar o sítio dos batimentos cardíacos no animal, foi realizado garrote no sentido cranial e caudal aos batimentos, e em seguida anti-sepsia do local com álcool iodado. A punção foi realizada com agulha fina $(25 \mathrm{x}$ $5,5 \mathrm{~mm}$ ) que era delicadamente inserida sob a escama em direção ao coração, obtendo-se o volume total máximo de $2 \mathrm{~mL}$ de sangue.

Os conjuntos seringa/agulha utilizados nas coletas foram previamente heparinizados para evitar a presença de coágulos na amostra, sendo este procedimento realizado através da aspiração de uma pequena quantidade de heparina sódica para a seringa de $3 \mathrm{~mL}$, lavando-a completamente, e despejando-se o volume de volta para o frasco de heparina.

$\mathrm{O}$ material foi mantido resfriado entre 1 e $6^{\circ} \mathrm{C}$, em recipiente de polímero expandido, até seu processamento no laboratório de Patologia Clínica do Instituto da Saúde e Produção Animal da Universidade Federal Rural da Amazônia, Campus Belém/PA, onde foi realizada a separação do plasma e o congelamento das amostras $\left(1^{\circ} \mathrm{C}\right)$ para o transporte até o Laboratório Paulo Azevedo, Unidade Hospital Porto Dias, Belém/PA, onde foram realizadas as dosagens bioquímicas de proteína total, albumina, globulina, alanina aminotranferase (ALT), aspartato amino transferase (AST), fosfatase alcalina (FA), desidrogenase láctica (DHL), ácido úrico, cálcio e fósforo, utilizando aparelho automático de bioquímica Biosystems A25 ${ }^{\circledR}$.

Os resultados foram analisados pelo ANOVA (Análise de Variância) e Kruskall Wallis para verificar se houve diferenças significativas entre os valores do verão amazônico com os do inverno amazônico, levando-se em consideração $\mathrm{P}<0,05$. 


\section{Resultados}

Os valores obtidos, levando em consideração a sazonalidade, estão expressos nas Tabelas 1 e 2 , e as comparações realizadas entre o verão amazônico e inverno amazônico para cada parâmetro, utilizando os testes de ANOVA e Kruskall Wallis estão ilustradas nas Figuras 1 a 10.

TABELA 1: Valores bioquímicos séricos de Boa constrictor constrictor mantidos em cativeiro durante o verão amazônico (agosto/2009), expressos por média aritmética, desvio padrão, limites inferior e superior de um desvio padrão, e valores mínimos e máximos de proteína total, albumina, globulina, ALT, AST, FA, DHL, ácido úrico, cálcio e fósforo. Belém. 2011.

\begin{tabular}{|c|c|c|c|c|c|c|}
\hline Parâmetro & Média & Desvio Padrão & $\begin{array}{l}\text { Limite } \\
\text { inferior }\end{array}$ & $\begin{array}{c}\text { Limite } \\
\text { Superior }\end{array}$ & Mínimo & Máximo \\
\hline Proteína total $(\mathrm{g} / \mathrm{dL})$ & 6,13 & 1,36 & 4,77 & 7,49 & 2,10 & 7,90 \\
\hline Albumina (g/dL) & 2,79 & 0,69 & 2,10 & 3,48 & 1,20 & 4,00 \\
\hline Globulina (g/dL) & 3,34 & 1,33 & 2,01 & 4,67 & 0,50 & 5,80 \\
\hline $\operatorname{ALT}(\mathrm{U} / \mathrm{L}) *$ & 7,68 & 7,05 & 0,64 & 14,73 & 2,00 & 27,00 \\
\hline $\operatorname{AST}(\mathrm{U} / \mathrm{L}) *$ & 12,35 & 7,01 & 5,34 & 19,36 & 4,00 & 31,00 \\
\hline FA (U/L) & 100,95 & 49,62 & 51,33 & 150,57 & 18,00 & 196,00 \\
\hline DHL (U/L) & 367,75 & 232,21 & 135,54 & 599,96 & 50,00 & 751,00 \\
\hline Ácido úrico (mg/dL) & 5,30 & 3,13 & 2,17 & 8,43 & 2,40 & 15,90 \\
\hline Cálcio $(\mathrm{mg} / \mathrm{dL}) *$ & 18,65 & 4,54 & 14,12 & 23,19 & 11,84 & 32,96 \\
\hline Fósforo (mg/dL) & 4,38 & 0,63 & 3,75 & 5,01 & 3,17 & 5,12 \\
\hline
\end{tabular}

*Parâmetros em que foram observadas diferenças estatísticas significativas $(\mathrm{P}<0,05)$ entre o inverno e verão amazônicos em ANOVA, Kruskall Wallis, e nos pós testes: Teste t e Comparações de Student-Newman-Keuls.

TABELA 2: Valores bioquímicos séricos de Boa constrictor constrictor mantidos em cativeiro durante o inverno amazônico (janeiro/2010), expressos por média aritmética, desvio padrão, limites inferior e superior de um desvio padrão, e valores mínimos e máximos de proteína total, albumina, globulina, ALT, AST, FA, DHL, ácido úrico, cálcio e fósforo. Belém. 2011.

\begin{tabular}{|c|c|c|c|c|c|c|}
\hline Parâmetro & Média & Desvio Padrão & $\begin{array}{c}\text { Limite } \\
\text { inferior }\end{array}$ & $\begin{array}{c}\text { Limite } \\
\text { Superior }\end{array}$ & Mínimo & Máximo \\
\hline Proteína total $(\mathrm{g} / \mathrm{dL})$ & 6,42 & 0,81 & 5,61 & 7,23 & 5,20 & 8,30 \\
\hline Albumina (g/dL) & 2,63 & 0,47 & 2,15 & 3,10 & 1,90 & 3,40 \\
\hline Globulina (g/dL) & 3,79 & 0,71 & 3,08 & 4,50 & 2,60 & 5,10 \\
\hline $\operatorname{ALT}(\mathrm{U} / \mathrm{L}) *$ & 12,95 & 8,88 & 4,07 & 21,83 & 0,00 & 27,00 \\
\hline $\operatorname{AST}(\mathrm{U} / \mathrm{L}) *$ & 20,60 & 8,67 & 11,93 & 29,27 & 5,00 & 41,00 \\
\hline $\mathrm{FA}(\mathrm{U} / \mathrm{L})$ & 129,33 & 71,18 & 58,15 & 200,52 & 36,00 & 268,00 \\
\hline DHL (U/L) & 452,90 & 143,04 & 309,87 & 595,94 & 233,00 & 879,00 \\
\hline Ácido úrico $(\mathrm{mg} / \mathrm{dL})$ & 6,09 & 4,49 & 1,60 & 10,58 & 2,20 & 22,30 \\
\hline Cálcio $(\mathrm{mg} / \mathrm{dL}) *$ & 21,25 & 1,24 & 20,71 & 23,20 & 20,31 & 25,78 \\
\hline Fósforo (mg/dL) & 4,26 & 0,60 & 3,66 & 4,86 & 2,83 & 5,30 \\
\hline
\end{tabular}

*Parâmetros em que foram observadas diferenças estatísticas significativas $(\mathrm{P}<0,05)$ entre o inverno e verão amazônicos em ANOVA, Kruskall Wallis, e nos pós testes: Teste t e Comparações de Student-Newman-Keuls. 
FIGURA 1: Comparação dos valores de proteína total no verão amazônico (Grupo A) e inverno amazônico (Grupo B), onde se observa que as médias e o desvio padrão entre os grupos são pouco divergentes, e um individuo apresentou no verão um outlier de $2,1 \mathrm{~g} / \mathrm{dL}$. AxB(P) ANOVA $=0,6355$ e $\mathrm{AxB}(\mathrm{P})$ Kruskal-Wallis $=0,7558$.

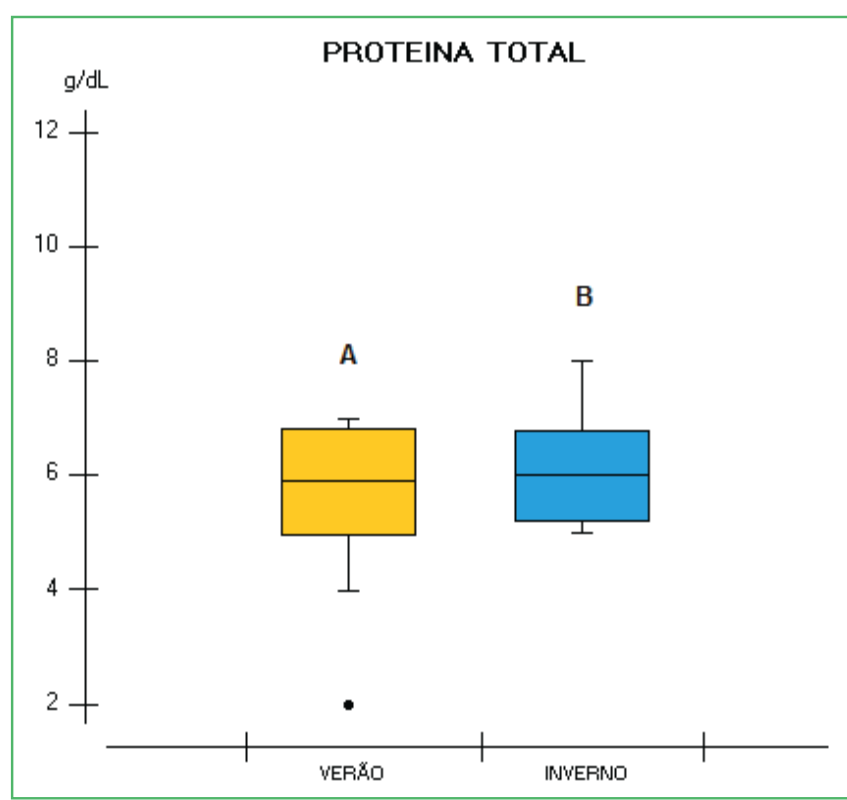

FIGURA 2: Comparação dos valores de albumina no verão amazônico (Grupo A) e inverno amazônico (Grupo $\mathrm{B})$, onde se observa que as médias e o desvio padrão entre os grupos pouco divergem $\mathrm{AxB}(\mathrm{P}) \mathrm{ANOVA}=$ 0,6870 e $\operatorname{AxB}(\mathrm{P})$ Kruskal-Wallis $=0,6039$.

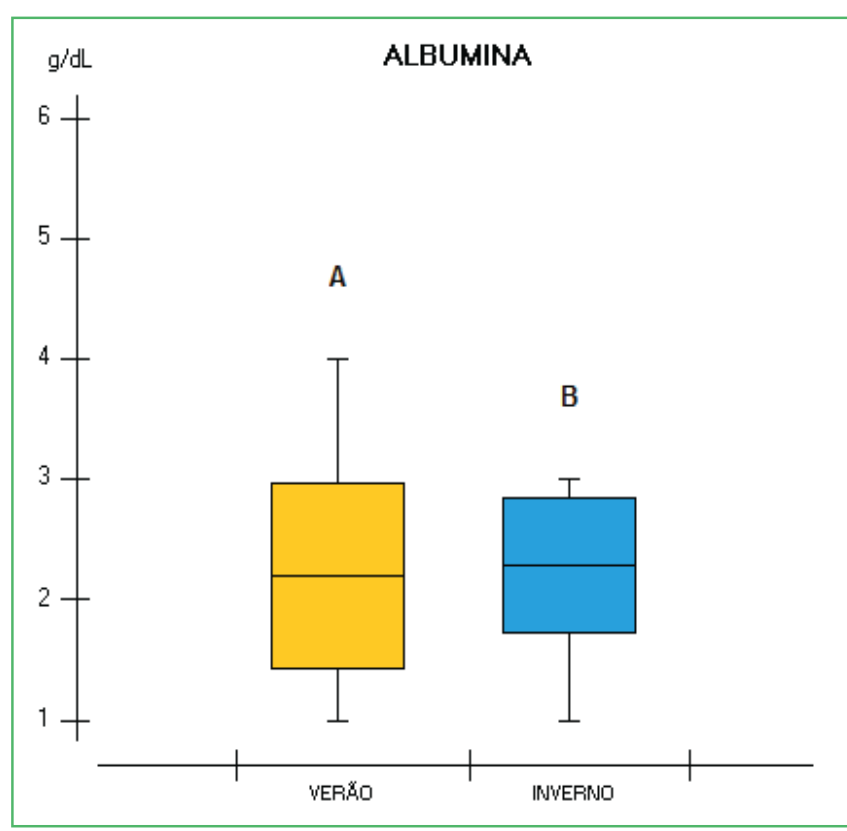

FIGURA 3: Comparação dos valores de globulina no verão amazônico (Grupo A) e inverno amazônico (Grupo B), onde se observa que a média no inverno é superior a do verão, mas estatisticamente não foi observado significância. $(p)$ ANOVA $=0,1277$ e $(p)$ KruskalWallis $=0,2128$.

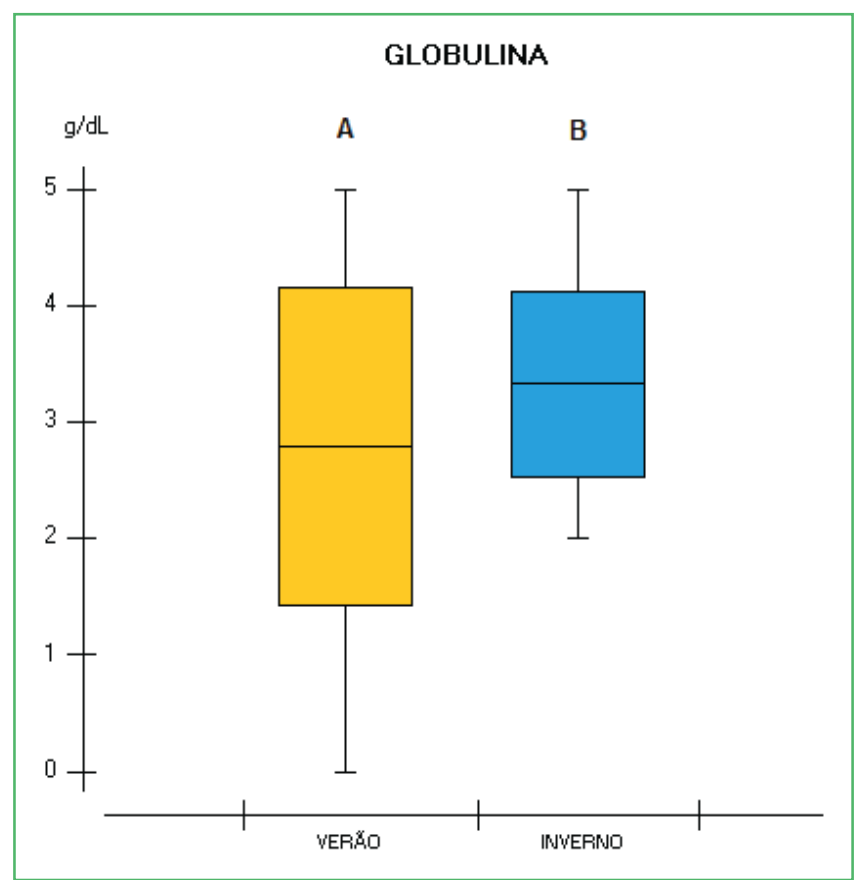

FIGURA 4: Comparação dos valores de alanino aminotransferase (ALT) no verão amazônico (Grupo A) e inverno amazônico (Grupo B), onde se observa que a média no inverno é superior a do verão e estatisticamente foi observada significância apenas na ANOVA e no Teste t. Um outlier de 27U/L foi observado no verão. $\mathrm{AxB}(\mathrm{P}) \mathrm{ANOVA}=0,0454$ e $\mathrm{AxB}(\mathrm{P})$ Teste $\mathrm{t}=0,0480$; $\mathrm{AxB}(\mathrm{P})$ Kruskal-Wallis $=0,0714$. * Parâmetro em que foram observadas diferenças estatísticas significativas $(\mathrm{P}<0,05)$ entre o verão e inverno amazônicos.

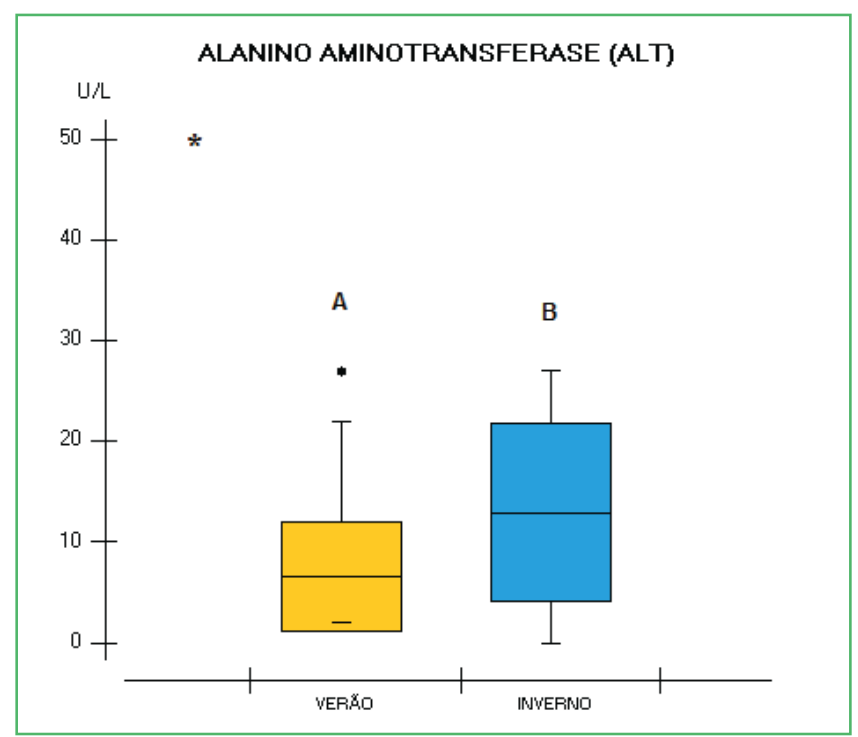


FIGURA 5: Comparação dos valores de aspartato aminotransferase (AST) no verão amazônico (Grupo A) e inverno amazônico (Grupo B) onde se observa que a média no inverno é superior a do verão e estatisticamente foi observado significância apenas em um teste e um pós-teste estatísticos. $\mathrm{AxB}(\mathrm{P}) \mathrm{ANOVA}=0,00240 \mathrm{e}$ $\mathrm{AxB}(\mathrm{P})$ Teste $\mathrm{t}=0,00240 ; \mathrm{AxB}(\mathrm{P})$ Kruskal-Wallis = 0,0022 e $\mathrm{AxB}(\mathrm{P})$ Comparações de Student-NewmanKeuls $=0,0022$ * Parâmetro em que foram observadas diferenças estatísticas significativas $(\mathrm{P}<0,05)$ entre $\mathrm{o}$ verão e inverno amazônicos.

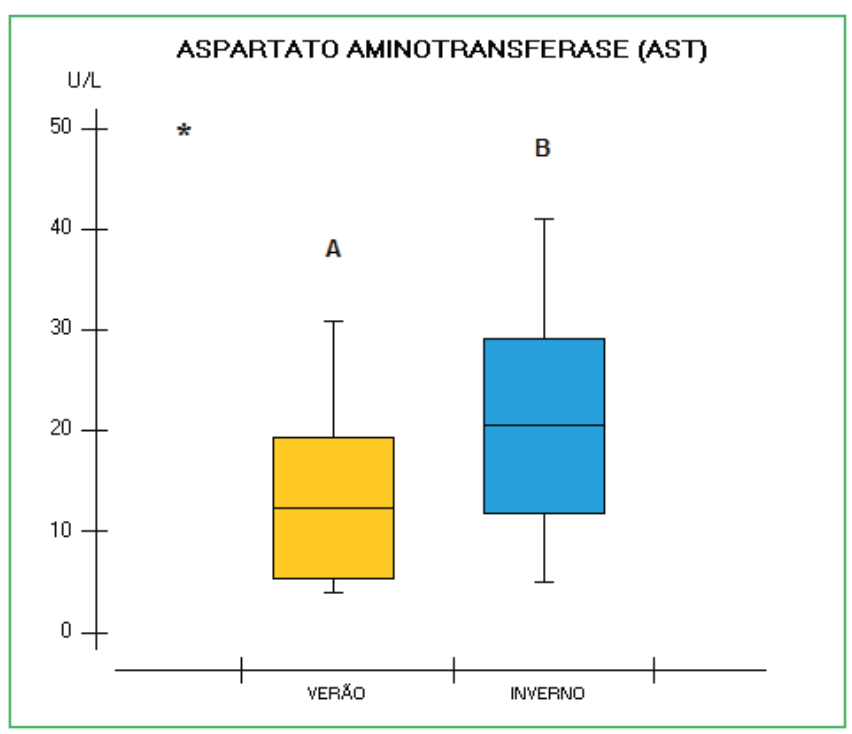

FIGURA 6: Comparação dos valores de fosfatase alcalina (FA) no verão amazônico (Grupo A) e inverno amazônico (Grupo B), onde se observa que a média no inverno foi superior a do verão, mas estatisticamente essa diferença não é significante. $(p)$ ANOVA $=0,1449$; (p) Kruskal-Wallis $=0,2457$.

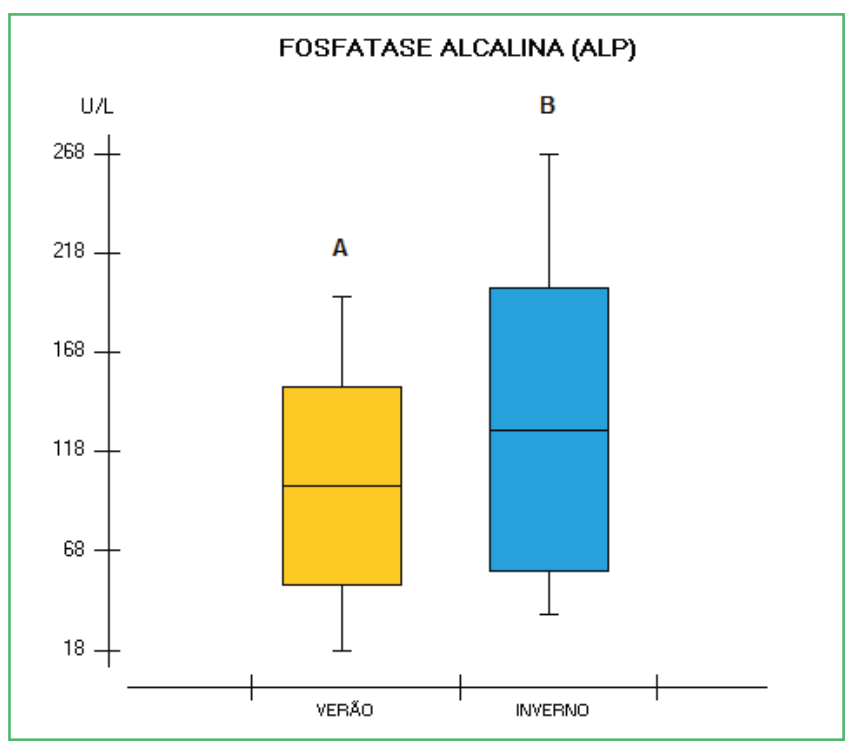

FIGURA 7: Comparação dos valores de desidrogenase láctica (DHL) no verão amazônico (Grupo A) e inverno amazônico (Grupo B), onde se observa que a média no inverno foi superior a do verão, mas estatisticamente essa diferença não é significante, um animal apresentou um outlier de 879,0 U/L AxB(P) ANOVA = 0,1597; AxB(P)Kruskal-Wallis = 0, 2908.

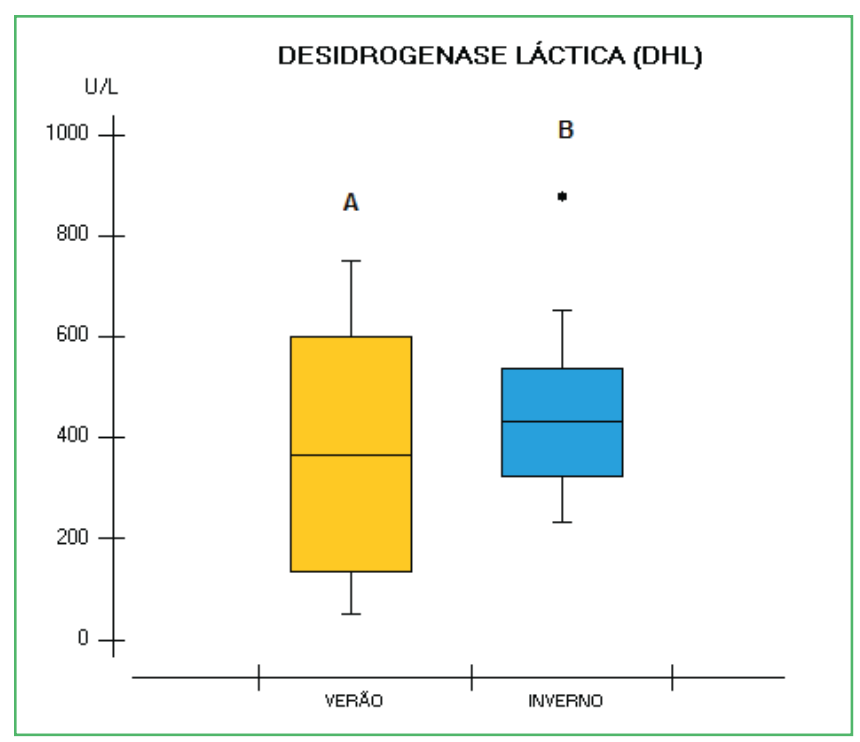

FIGURA 8: Comparação dos valores de cálcio sérico no verão amazônico (Grupo A) e inverno amazônico (Grupo B), onde se observa que a média no inverno é superior a do verão e estatisticamente foi observado significância. Um individuo no verão apresentou um outlier de $32,96 \mathrm{mg} / \mathrm{dL}$ e outro apresentou no inverno um de 25,78mg/dL. AxB(P)ANOVA $=0,0023 \mathrm{e}$ $\mathrm{AxB}(\mathrm{P})$ Teste $\mathrm{t}=0,0019 ; \mathrm{AxB}(\mathrm{P})$ Kruskal-Wallis $=$ 0,0001 e $\mathrm{AxB}(\mathrm{P})$ Student-Newman-Keuls $=0,0001$. *Parâmetro em que foram observadas diferenças estatísticas significativas $(\mathrm{P}<0,05)$ entre o verão e inverno amazônicos.

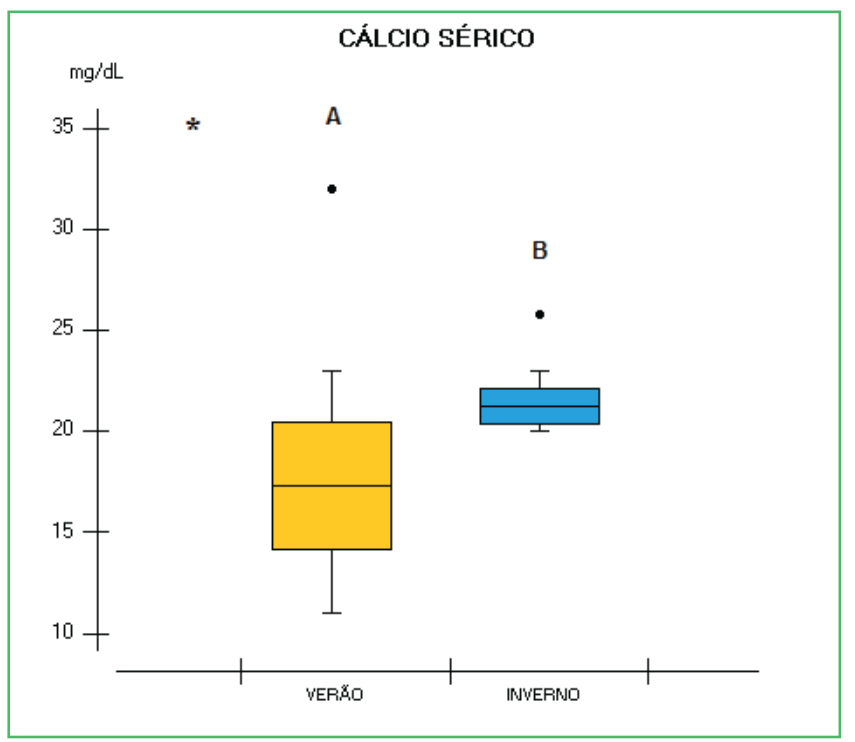


FIGURA 9: Comparação dos valores de ácido úrico no verão amazônico (Grupo A) e inverno amazônico (Grupo B), onde se observa que a média e desvio padrão foram pouco divergentes. Um individuo apresentou um outlier de $15,9 \mathrm{mg} / \mathrm{dL}$ no verão, e no inverno um individuo apresentou um de $12,8 \mathrm{mg} / \mathrm{dL}$ e um outro de $22,3 \mathrm{mg} / \mathrm{dL} . \mathrm{AxB}(\mathrm{P}) \mathrm{ANOVA}=0,9880$ e $\mathrm{AxB}(\mathrm{P})$ Kruskal-Wallis $=0,08743$.

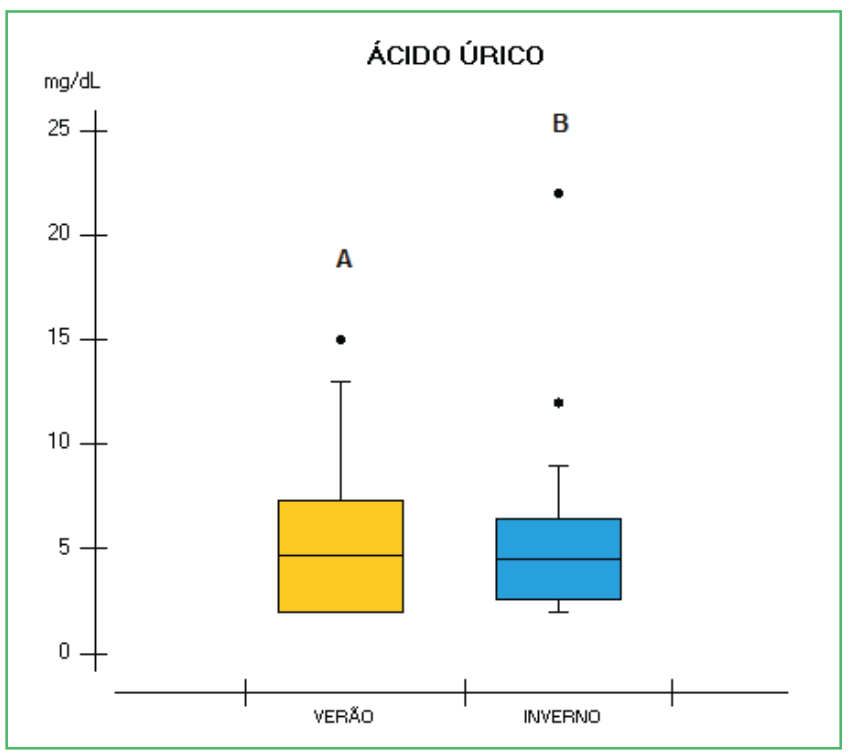

FIGURA 10: Comparação dos valores de fósforo sérico no verão amazônico (Grupo A) e inverno amazônico (Grupo B) onde se observa que as médias e desvio padrão foram pouco divergentes, uma discreta diminuição dos valores de fósforo pode ser observada no inverno em comparação com o verão. AxB(P)ANOVA = 0,6564 e $\mathrm{AxB}(\mathrm{P})$ Kruskal-Wallis $=0,8062$.

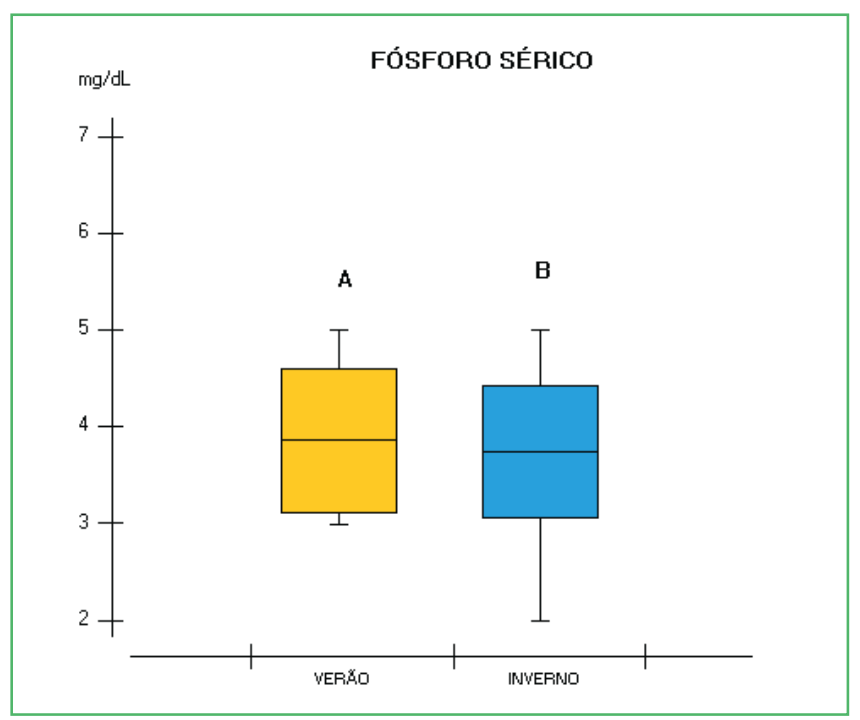

\section{Discussão}

Após analise estatística, foi detectado que durante o inverno amazônico, oito dos dez parâmetros bioquímicos (proteína total, albumina, globulina, ALT, AST, FA, DHL e cálcio) estiveram com os valores médios superiores aos do verão amazônico. Apenas o ácido úrico e o fósforo tiveram seus valores médios do inverno amazônico inferiores aos do verão amazônico.

Durante o inverno amazônico, os valores de proteína total e frações foram discretamente superiores, porém essas diferenças não foram estatisticamente significantes $(\mathrm{P}<0,05)$ (Figuras 1,2 e 3$)$. Esse achado, não foi suficiente para sugerir que os animais apresentam hiperproteinemia durante o inverno, pois segundo Campbell (2006a), em répteis só se considera hiperproteinemia quando os valores de proteínas totais são superiores a $7 \mathrm{~g} / \mathrm{dL}$, e no presente estudo estiveram em $6,42 \pm 0,82 \mathrm{~g} / \mathrm{dL}$.

Segundo Campbell (2006b), uma das causas de hiperproteinemia em reptéis (principalmente hiperglobulinemia) pode ser decorrente de processos inflamatórios e infecciosos. Nas fêmeas, pode ocorrer por indução de estrógenos durante a foliculogênese ativa, onde há uma diminuição de albumina e elevação das globulinas. Estes valores retornam ao normal após a ovulação.

Em relação a função hepática dos animais estudados, observou-se que a atividade das enzimas hepáticas estiveram todas notadamente superiores durante o inverno amazônico em relação ao verão amazônico (Figuras 4, 5, 6 e 7).

A alanina aminotransferase (ALT) mostrou ter diferença estatística significativa apenas no teste de ANOVA ( $\mathrm{P}=0,0454)$ e no pós teste com Teste $\mathrm{t}$ ( $\mathrm{P}$ $=0,0480$ ), porém, o mesmo não ocorreu quando os dados foram analisados por Kruskal-Wallis ( $\mathrm{P}=0,0714)$.

A aspartato aminotransferase (AST) apresentou diferença estatística significante $(\mathrm{P}<0,05)$ em ANOVA e Kruskall Wallis, que foi confirmada nos pós testes com Test t e Comparações de Student-Newman-Keuls.

Segundo Campbell (2006a), os valores de ALT geralmente são inferiores a $20 \mathrm{U} / \mathrm{L}$, assim como demonstrado nos valores médios encontrados na presente 
pesquisa, porém aumentos de AST e DHL são mais confiáveis para detecção de doença hepatocelular em répteis, já que possuem altas atividades no tecido hepático.

Os valores de atividade de AST e DHL devem ser inferiores a $250 \mathrm{U} / \mathrm{L}$ e $1000 \mathrm{U} / \mathrm{L}$, respectivamente, sendo que a elevação destas duas enzimas acima do referencial proposto pode sugerir doença hepatocelular, lesão hepática, lesão de músculo esquelético ou de músculo cardíaco (CAMPBELL, 2006a). Os resultados do presente estudo obtiveram médias para as emzimas AST e DHL, respectivamente, no inverno de

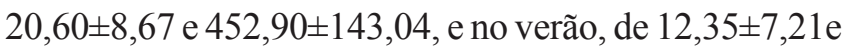
$367,75 \pm 232,21$ e portanto, não ultrapassaram estes valores de referência, indicando não haver indícios de lesões hepática, muscular ou cardíaca.

Quanto à atividade da fosfatase alcalina (FA) e da desidrogenase láctica (DHL) observou-se uma elevação dos valores médios durante o inverno, com valores de $129,33 \pm 71,18$ e $452,90 \pm 143,04$, respectivamente, porém esses resultados não foram estatisticamente significativos.

Apesar da enzima FA apresentar baixa especificidade (LASSEN, 2006) e existirem poucas informações a respeito da interpretação do aumento de sua atividade na espécie estudada (CAMPBELL, 2006a), acredita-se que tal diferença possa estar associada com uma discreta sobrecarga do fígado, levando em consideração que a maior porcentagem de AST, DHL e FA séricas são de origem hepática (LASSEN, 2006) e que segundo Denardo (2006), como a fisiologia dos répteis é muito afetada pela diminuição de temperatura imposta pelo ambiente, a maioria dos sistemas do corpo, incluindo o sistema digestório e imunológico acabam sendo menos eficientes durante o resfriamento sazonal, não sendo considerada, entretanto, disfunção hepática importante.

De acordo com Dias Figueirosa e Mitchel (2006), a taxa de digestão para répteis pode depender de uma série de fatores, incluindo a temperatura corporal, o estado de hidratação, tipo de alimento, tamanho da refeição e a saúde geral do réptil. Portanto, a falta de temperatura ambiental adequada pode levar à diminuição da motilidade gastrintestinal, do tempo para a digestão, da produção de enzimas e ácidos, podendo até mesmo levar a putrefação da digesta (DIAS FIGUEIROSA; MITCHEL, 2006), o que ocasionaria um maior esforço hepático para tentar manter as atividades e realizar a digestão durante as estações mais frias.

De acordo com Campbell (2006b), considera-se hipercalcemia quando a concentração plasmática de cálcio supera $20 \mathrm{mg} / \mathrm{dL}$, o que foi observado durante o inverno amazônico, onde os valores médios de cálcio foram de $21,95 \pm 1,24$, enquanto que no verão foram de 18,65 $\pm 4,54$ (Figura 8). Observou-se também, que o desvio padrão do cálcio no inverno amazônico foi consideravelmente menor em comparação com o do verão amazônico $( \pm 4,54)$, o que significa que os dados obtidos durante o inverno amazônico foram mais uniformes.

Acredita-se que a hipercalcemia possa ocorrer por causa do ciclo reprodutivo das fêmeas, que de acordo com Campbell (2006a), exibem características do metabolismo do cálcio semelhantes às de aves em fase de produção de ovos e também em resposta ao estrógeno e à atividade reprodutiva, onde podem ser observados valores de cálcio séricos de duas a quatro vezes o valor normal.

Neste estudo, tanto os machos quanto as fêmeas, apresentaram valores séricos de cálcio notadamente maiores do que no verão amazônico, portanto a possibilidade de que o cálcio sérico elevado é devido a atividade aumentada de estrógenos e mobilização de cálcio para a formação do ovo foi descartada, pois este evento só acontece nas fêmeas, e não foi achado uma correlação que justifique estes valores elevados de cálcio tanto em fêmeas, quanto em machos durante o inverno amazônico.

Em relação à avaliação da função renal, observou-se que os valores de ácido úrico e fósforo foram discretamente maiores no verão amazônico em comparação com o inverno amazônico e não demonstraram ter diferença estatística significativa (Figuras 9 e 10). Porém, segundo Campbell (2006a), o ácido úrico não é um indicador sensível, tampouco específico, de doença renal em répteis, e seu valor pode encontrar-se, normalmente, de 1,5 a 2 vezes maior em animais carnívoros no dia seguinte à alimentação.

Para Mitchell (2009), a função renal pode ser melhor avaliada através da relação de proporção com 
a dosagem de cálcio e fósforo, que nas serpentes saudáveis é de aproximadamente 1,5:1 a 2:1, sendo que em animais com problemas renais essa relação tende a diminuir. Neste estudo, a função renal das serpentes, estava normal, já que essa relação cálcio/fósforo durante o verão e o inverno amazônico foram de 4,25:1 e 5,15:1, respectivamente.

Segundo Fettman e Rebar (2006), hipofosfatemia pode ocorrer em casos de hipercalcemia por condições patológicas como distúrbios osteometabólicos, hiperparatireoidismo, pseudo-hiperparatireoidismo, porém, apesar desses valores elevados de cálcio, neste estudo não foi observado hipofosfatemia significante durante o inverno amazônico.

Os resultados do presente estudo foram parcialmente diferentes dos obtidos por Machado et al. (2005) em Boa constrictor amarali, pois estes autores demonstraram que os animais apresentaram valores mais elevados de AST no verão em relação ao inverno $(\mathrm{P}<0,05)$ e valores mais elevados para ácido úrico no inverno que no verão $(\mathrm{P}<0,05)$, sendo que as demais variáveis não sofreram influência sazonal.

Observou-se que oito dos dez parâmetros são maiores no inverno em comparação ao verão (proteína total, albumina, globulina, ALT, AST, FA, DHL e cálcio) e que apenas o ácido úrico e fósforo foram menores no inverno amazônico em relação ao verão amazônico.

Os valores de cálcio são os que mais apresentaram diferenças significantes levando em consideração a sazonalidade, mas não encontrou-se uma correlação para tal evento, sendo necessário mais estudos a respeito do comportamento deste mineral em Boa constrictor constrictor.

Esta foi a primeira pesquisa realizada em animais em cativeiro, analisando o perfil bioquímico sérico de Boa constrictor constrictor no Estado do Pará.

\section{Referências}

BOVO, R. P.; MICHELI, M. A.; ABE, A. S.; ANDRADE. Variação sazonal da temperatura corpórea em jibóias, Boa constrictor amarali. In: CONGRESSO BRASILEIRO DE ZOOLOGIA, XXV, 2004, Brasília. Anais... Brasília: CBZ, 2004. p. 387.

CAMPBELL, T. W. Bioquímica clínica de Répteis. In: THRALL,
M. A.; BAKER, D. C.; CAMPBELL, T. W.; DENICOLA, D.; FETTMAN, M. J.; LASSEN, E. D.; REBAR, A.; WEISER, G. (Ed.). Hematologia e bioquímica clínica veterinária. São Paulo: Roca, 2006a. p. 462-466.

CAMPBELL, T. W. Clinical pathology of Reptiles. In: MADER, D. R. (Ed.). Reptile Medicine and Surgery. Florida: Ed. Sauders Elsevier Inc. Marathon, 2006b. p. 453-470.

DENARDO, D. Reproductive biology. In: MADER, D. R. (Ed.). Reptile Medicine and Surgery. Florida: Ed. Sauders Elsevier Inc. Marathon, 2006. p. 376-390.

DIAS FIGUEIROSA, O.; MITCHELL, M. A. Gastrointestinal anatomy and physiology. In: MADER, D. R. (Ed.). Reptile Medicine and Surgery. Florida: Ed. Sauders Elsevier Inc. Marathon, 2006. p. 145-162.

FETTMAN, M. J.; REBAR, A. Avaliação laboratorial da função renal. In: THRALL, M. A.; BAKER, D. C.; CAMPBELL, T. W.; DENICOLA, D.; FETTMAN, M. J.; LASSEN, E. D.; REBAR, A.; WEISER, G. (Ed.). Hematologia e bioquímica clínica veterinária. São Paulo: Roca, 2006. p. 285-309.

FOWLER, M. E.; CUBAS, Z. S. Biology, medicine and surgery of South American wild animals. 1 ed. Ames: Iowa State University Press, 2001. $536 \mathrm{p}$.

HIINAREJOS, D. P.; HERNÁNDEZ-DIVERS, S. M.; HERNÁNDEZ-DIVERS, S. J. Ofídios. In: AGUILAR, R.; HERNÁNDEZ-DIVERS, S. M.; HERNÁNDEZ-DIVERS, S. J (Ed.). Atlas de medicina, terapêutica e patologia de animais exóticos. São Paulo: Interbook. 2007. p. 119-140.

IIZUKA, H.; CANTER, H. M.; OLIVEIRA, E. P. T.; HIGASHI, H. G.; ROSA, R. R. Estomatite ulcerativa infecciosa em Boa constrictor constrictor mantidas em cativeiro. Memórias do Instituto Butantan, São Paulo, v. 47/48, p. 113-120, 1984.

JACOBSON, E.R. Reptiles exotic pet medicine. Veterinary Clinics North American Smal Animal Practice, Philadelphia, v. 17, p. 1203-1225, 1987.

KOLESNIKOVAS, C. K. M.; GREGO, K. F.; ALBUQUERQUE, L. C. R. Ordem Squamata. In: CUBAS, Z. S.; SILVA, J. C. R.; CATÃO-DIAS, J. L. (Ed.). Tratado de animais selvagens medicina veterinária. São Paulo: Roca, 2006. p. 58-67.

LASSEN, E. D. Avaliação laboratorial do fígado. In: THRALL, M. A.; BAKER, D. C.; CAMPBELL, T. W.; DENICOLA, D.; FETTMAN, M. J.; LASSEN, E. D.; REBAR, A.; WEISER, G. (Ed.). Hematologia e bioquímica clínica veterinária. São Paulo: Roca, 2006. p. 340-341.

MACHADO, C. C.; SILVA, L. F. N.; RAMOS, P. R. R.; TAKAHIRA, R. K. Influência sazonal sobre os valores bioquímicos, hematológicos e de eletroforese de hemoglobinas de jibóias - Boa constrictor amarali (Linnaeus, 1758). WORKSHOP BRASILEIRO DE HEMATOLOGIA DE RÉPTEIS, I, 2005, Vila Velha. Anais... Vila Velha, ES, 2005. p. 11.

MITCHELL, M. A. Snakes. In: MITCHELL, M. A. (Ed.). Manual of exotic pet practice. St. Louis: Elsevier Saunders, 2009. p. 136-163.

MOSMANN, M. N. Guia das principais serpentes do mundo. v. 1. Canoas: Editora Ulbra, 2001. 392 p.

SANTOS, E. O. Perfil bioquímico-hematológico em lhamas (Lama glama - Linnaeus 1758) criadas em cativeiro no sul do país: variações de gênero e época do ano. Porto Alegre: UFRGS, 2006. CDD 619.6026. 